\title{
Management and control of an outbreak of fatal truamatic myiasis due to Chrysomya bezziana in a herd of Persian Fallow Deer (Dama dama mesopotamica)
}

Ehsan Gharib Mombeni ${ }^{* *}$, Manoochehr Gharib Mombeini², Mehdi Khalaj ${ }^{3}$, Morad Moradi Garavand ${ }^{4}$, Abdul Amir Rezaei ${ }^{5}$, Ahmadreza Lahijanzadeh $^{6}$, Mostafa Kenarkohi ${ }^{7}$, Seyed Adel Mola ${ }^{8}$, Seyed Kamin Hosseini ${ }^{9}$

${ }^{1}$ Expert of Animal Diseases Control and Monitoring, Ahvaz Veterinary Organization, Khuzestan province, Iran

${ }^{2}$ Provincial Animal Diseases Control and Monitoring, Khuzestan province Veterinary Organization, Iran

${ }^{3}$ Head of Iran Veterinary Organization, Iran

${ }^{4}$ Senior Expert of Hygiene Department and Mycobacterial Disease Control, Iran

${ }^{5}$ General Director of Veterinary Public Health and Animal Disease Management, Tehran, Iran

${ }^{6}$ Senior Manager Environmental Protection, Khuzestan Province, Iran

${ }^{7}$ Director of Khuzestan province Veterinary Organization

${ }^{8}$ Senior Expert Environmental Protection, Khuzestan Province, Iran

${ }^{9}$ Senior Manager of Iranian Nature Preservation Organization at Helveh Park, Khuzestan Province, Iran

\begin{abstract}
Cutaneous myiasis caused by the Chrysomya bezziana in Asian and African countries is common in wild and domestic mammals. A herd of Persian fallow deer $(n=80$, consisting of adult and young male and female animals) with an average age range of 3 months to 6 years was viewed. Observed were 40 deaths putting the heard near to extinction. The animals were found with traumatic cutaneous wounds mostly in one ear, the eyes and head as well as the ventral part of the neck. The ears were necrotised and could no longer remain upright; the wounds were full of maggots of different sizes and stages of development. Based on morphological features, the collected larvae were examined by a central Khuzestan veterinary laboratory and identified as $C$. bezziana larvae. This is the first ever occurrence of $C$. bezziana that caused such a population reduction of these wonderful animals in a herd of Persian fallow deer held under the supervision of Iranian Nature Preservation Organization and kept at Helveh Park in Shush county (East-South of Iran) where original ecology and its treatment and control of myiasis have been discussed. This paper is apparently the first report of an infestation of cutaneous myiasis due to $C$. bezziana in Persian fallow deer. Also we report high infestation Rhipicephalus microplus as an important ectoparasite of these Persian fallow deer that has been never discussed before.
\end{abstract}

Keywords: Chrysomya bezziana; Iran; Myiasis; Persian Fallow Deer; Rhipicephalus microplus

\section{Introduction}

The Persian Fallow Deer (Dama dama mesopotamica) is an extremely ancient and rare ruminant mammal belonging to the family Cervidae. Its classified status is argue, with some maintaining it is a subspecies of the Fallow Deer, while others treat it as a separate species, Dama mesopotamica. The Persian Fallow Deer is the most endangered species in the world and is only found in a few protected areas in the northwest north and southwest of Iran. It is known as one of Iran's wildlife species. In 1956, a few of the animals animals were seen in riverine habitats in southwestern Iran (Dez river, Karkheh area), and from 1957-58 one wild pair of pureblood fawns was brought from southwest Iran to the Von Opel Zoo in Germany after an expedition to the Karkheh area. The wild female gave birth to its first pureblood female in 1960. From 1964 to 1967 , the Iranian Wildlife Refuges Department sent three expeditions to the Karkheh area, near the place where the species was rediscovered. As a result of these expeditions, six animals were captured ( 3 males, 3 females) in order to begin the species' conservation at the Dasht-e-Naz (near the southern shore of the Caspian Sea) and the Karkheh Wildlife Refuges. One of the males was sent to Germany in 1964 as part of the European captivity breeding program [1-3].

Cutaneous myiasis is caused by the Old World screw-worm fly, Chrysomya bezziana. Their larvae feed and develop in the cutaneous tissues of their hosts, causing severe trauma in a wide spread of domestic animals, as well as humans, in Southeast Asian and African countries. There is a higher incidence of myiasis infecting domestic animals, such as livestock on farms and household pets, leading to health injuries of these animals and economic loss. However, in wild animals myiasis infection leads to severe reduction of species populations until extinction. Ivermectin has been used for endoparasitic and ectoparasitic treatment in domestic animals, but unfortunately its efficacy, dosage, and safety in wild deer has not been reported previously [4].

Myiasis infestation of Persian fallow deer has never been reported previously. To our knowledge, this is the first report of the oppressive outbreak of myiasis in deer, and our intention is to promote better management of outbreaks of myiasis infestation. Additionally, we explore the interesting possibility that this method of treatment for prevention and control of this disease in wildlife could result in the protection of rare animals and prevent the extinction of any species.

Ticks are obligate hematophagous arthropods belonging to the class Arachnida, and are blood-feeding ectoparasites of vertebrates,

*Corresponding author: Ehsan Gharib Mombeni, Expert of Animal Diseases Control and Monitoring, Ahvaz Veterinary Organization, Khuzestan province, Iran, Tel: +98 6114471450 E-mail: E.Mombeni@hotmail.com

Received September 28, 2013; Accepted February 12, 2014; Published February 14,2014

Citation: Mombeni EG, Mombeini MG, Lahijanzadeh A, Kenarkohi M, Mola SA et al. (2014) Management and control of an outbreak of fatal truamatic myiasis due to Chrysomya bezziana in a herd of Persian Fallow Deer (Dama dama mesopotamica). J Veterinar Sci Technol 5: 157. doi:10.4172/2157-7579.1000157

Copyright: (c) 2014 Mombeni EG, et al. This is an open-access article distributed under the terms of the Creative Commons Attribution License, which permits unrestricted use, distribution, and reproduction in any medium, provided the original author and source are credited. 
Citation: Mombeni EG, Mombeini MG, Lahijanzadeh A, Kenarkohi M, Mola SA, et al. (2014) Management and control of an outbreak of fatal truamatic myiasis due to Chrysomya bezziana in a herd of Persian Fallow Deer (Dama dama mesopotamica). J Veterinar Sci Technol 5: 157. doi:10.4172/2157-7579.1000157

Page 2 of 4

particularly mammals. They are relatively large, and stages are long-lived, feeding periodically by taking large blood meals. Heavy infestations cause anemia in the host. High tick burdens may also cause severe skin irritation, which forces hosts to rub and scratch their skin; hair loss and dermatitis can develop, accompanied by hyperkeratosis, giving the skin a leathery texture. Dermal lesions associated with tick feeding predispose the host to microbial invasion, which can lead to deeper dermal infection.

In addition to the direct effects associated with blood feeding, ticks also transmit disease-causing agents. Ticks and tick-borne diseases cause significant economic losses to the livestock industry. They impede the introduction of highly productive breeds into tropical and subtropical areas of the world. In economic terms, the cattle tick Rhipicephalus microplus is considered to be the most important ectoparasite of livestock globally. This cattle tick species also serves as a vector of Babesia bovis and Babesia bigemina, which cause bovine babesiosis, and Anaplasma marginale, which causes anaplasmosis in cattle. The direct or indirect economic losses resulting from tick infestation could also be considered as an important factor that impedes the establishment of exotic animals for production purposes in tropical regions [5]. R. microplus parasitizing Persian fallow deer has not been reported previously. In this study, $R$. microplus has been reported as an important ectoparasite of these deer.

\section{Materials and Methods}

This study was carried out on forty pairs of Persian fallow deer within the wide age range of 3 months to 6 years. The deer are housed in a collection of the Iranian Nature Preservation Organization at Helveh Park in Shush county. The Helve site encompasses 200 hectares enclosed by 2.5 -metre-high woven-wire fences that protect the wildlife from domestic animals.

The deer were first captured in vertical long nets and immobilized with xylazine hydrochloride $(0.5 \mathrm{mg} / \mathrm{kg})$ and ketamine hydrochloride $(2 \mathrm{mg} / \mathrm{kg})$ using 1.5-inch needles. Following handling for treatment and central measures, the animals were transported with care to the central camp. After some injuries were noted because of the method used, the animals to be captured were administered explosive-charge darts with soft collars and 1.5-inch needles (Pneu-dart Inc., Williamsport, PA) fired from a $\mathrm{CO}_{2}$-powered rifle (Dan-Inject1, Fort Collins, $\mathrm{CO}$ ).

In the third stage, larvae and flies of C. bezziana were collected in normal saline and alcohol ethylic 70\%, respectively. Identification was carried out in the laboratory as per Zumpt (1965).

For tick sampling, at least 50 ticks were removed manually from the deer and sorted according to the development stage and sex of adult ticks before being transferred to sterile tubes and transported at $4^{\circ} \mathrm{C}$ to the Parasitology Laboratory at the Central Veterinary Laboratory of the Veterinary Organization of Khuzestan province.

\section{Results}

The most mature collected larvae were cream in colour and 12 to $17 \mathrm{~mm}$ in size with a tapered anterior and a typical muscoid shape. At the anterior end, they were armed with minute paired hooks. These hooks connected posteriorly with the black cephalopharyngeal skeleton that was visible internally through the prothorax in the cephalic region of the larvae body. They possessed cuticular inter-segmental transverse bands of spines except on the last segment. Furthermore, only half of $12^{\text {th }}$ posterior segment was pigmented. The stigma plates were dark black in colour and open (Figure 1).

Upon examining the anaesthetized animals, wounds were observed in one ear and/or near both eyes in most of deer. A very heavy infestation of maggots was found in all areas surrounding the ears, eyes and foreheads. For the haematological examination, $5 \mathrm{ml}$ of blood was taken in the EDTA vacuum tube.

The maggots were removed manually from the wound by using forceps. Any remaining deep-seated maggots were killed and extracted by using $100 \mathrm{ml}$ paraffin mixed with $5 \mathrm{ml}$ MAC-Tomeil (Cypermethrin 10\%) in the open wounds for 30 minutes. This procedure drew out and killed the maggots that had perforated deeply into the wounds. Forceps were used to remove both the dead and live maggots and fly eggs on the surface of the wounds. The wounds were dressed with Povidone-iodine $10 \%$.

The animals were trimmed with the Ivermectin, an antibiotic and an anti-inflammatory. The animals were injected deep into the muscle with Pen-Strep 3+3 (dosage 1 million units per body) and Phenilbutazon $20 \%$ (dosage $2.5 \mathrm{mg} / \mathrm{kg}$ body weight) by using darts rifle for 3 days. The Ivermectin $1 \%$ was injected $300 \mathrm{ug} / \mathrm{kg}$ subcutaneously in one dose on the first day.

The maggots were completely absent from the wounds on the 1th day of the first day. Spray Oxytetracycline (OTC) was routinely sprayed on the wounds every third day. The haematology showed an increase in the leucocytes count, which showed the intensity of secondary bacterial infection. The usage of pen-strep has taken control of the secondary bacterial infection. To avoid a secondary bacterial infection because of the open wounds and no presence of maggots, the protective tissues were treated with antibiotics and anti-inflammatory. All of the ticks collected from the Persian fallow deer were identified as R. microplus (Figure 2).

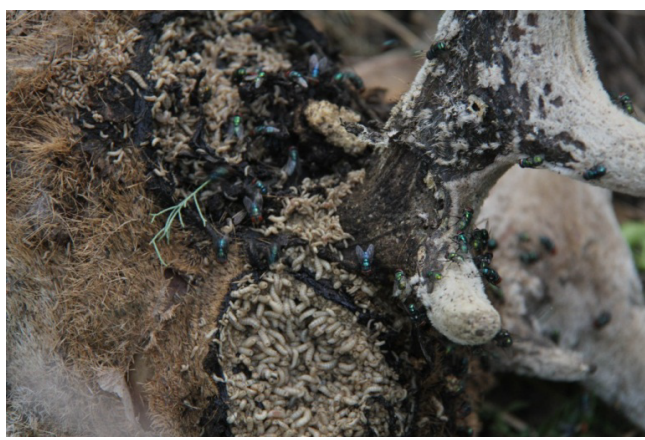

Figure 1: Dead Persian fallow deer highly infested with $C$. bezziana. High larvae infestation on head and into ears causes necrosis ears.

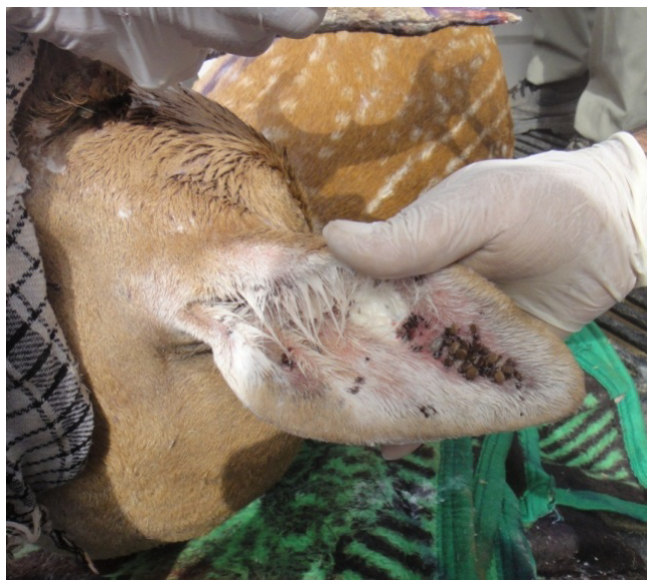

Figure 2: Anesthesia Persian fallow deer highly infested with Rhipicephalus microplus. Tick infestation on head and into ears. 
Citation: Mombeni EG, Mombeini MG, Lahijanzadeh A, Kenarkohi M, Mola SA, et al. (2014) Management and control of an outbreak of fatal truamatic myiasis due to Chrysomya bezziana in a herd of Persian Fallow Deer (Dama dama mesopotamica). J Veterinar Sci Technol 5: 157. doi:10.4172/2157-7579.1000157

Necropsies did not reveal the signs of any other pathogens, particularly gastrointestinal parasites, and the blood analysis did not reveal the presence of any blood parasite.

\section{Discussion}

The morphological characteristics of palmate-shaped anterior spiracles situated on the dorso-posterior margin of the $2^{\text {nd }}$ segment with 4-6 lobes arranged in a single row confirmed the identification as Chrysomya bezziana larvae.

C. bezziana is an obligate parasite of mammals, which lays its eggs and whose larvae grow in necrotic tissues and/or wounds. The larvae secrete enzymes which liquefy the skin and flesh of the animal, allowing the larvae to penetrate deeply into the tissues with their strong oral hooks. The larvae burrow into the healthy tissues surrounding wounds and can also penetrate into bones close to wounds. However, in this outbreak, obligatory myiasis was primarily observed in the absence of wounds. Animals which live or spend a great deal of time outside are most at risk of C. bezziana, especially animals with draining wounds, inflamed tissues, or high levels of tick infestation. The infested animals showed obvious signs of distress, and when their condition progressed, they demonstrated recumbancy in the sensitive parts of their body (Figures 3-5). The lesions and the presence of maggots therein are painful. The animals spend less time grazing and more time rubbing and biting the affected body areas. The presence of secondary bacterial infection may lead to death from septicemia or toxaemia, causing huge losses in terms of species variety and extinction to wildlife. C. bezziana flies also attack human beings and the larvae may be found in various tissues, such as the scalp, eye, subdermis of the throat, mouth, feet, and gangrenous wounds [6]. The larvae invade foul smelling or suppurated wounds, particularly

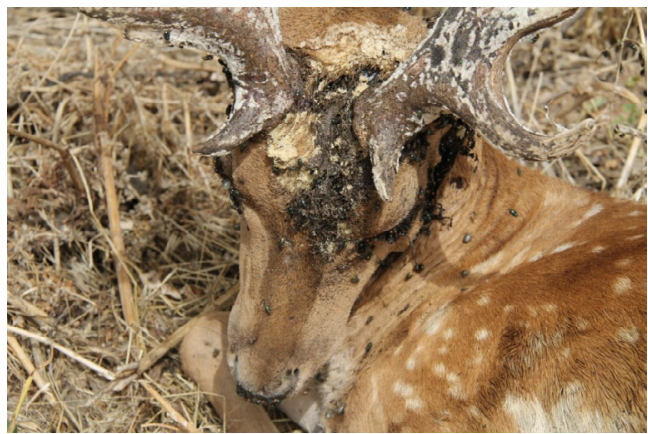

Figure 3: Dead Persian fallow deer highly infested with $C$. bezziana. High larvea infestation on head and into ears causes necrosis ears.

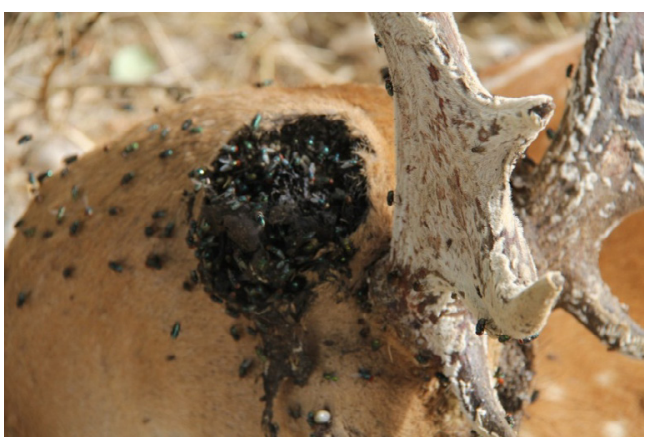

Figure 4: Dead Persian fallow deer highly infested with $C$. bezziana. High larvea infestation on head and into ears causes necrosis ears.

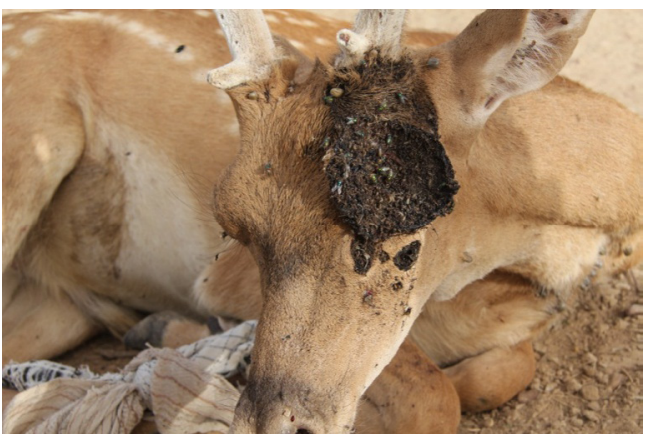

Figure 5: Live blinded two eases Persian fallow deer highly infested with $C$. bezziana. High larvae infestation into eases causes blind.

in rural areas where humans may come in direct contact with the animal population, in elderly or handicapped individuals, or in populations who live in poor hygienic conditions [4]. In view of the significance of C. bezziana in terms of public health and the extinction of wildlife, there is an immediate need to conduct a systematic planned epidemiological survey to determine the status of $C$. bezziana in domestic and wild animals, especially in rare wild animals, and to formulate an appropriate control and treatment strategy to minimise the perpetuating financial and irreversible losses caused by infested domestic animals, wild animals and animal owners in the region.

Heavy infestation with Rhipicephalus microplus may cause severe skin irritation, which forces the host to rub and scratch their skin. This in turn causes dermal lesions associated with tick feeding, and predisposes the host to microbial invasion, which can lead to deeper dermal infection [5]. In the first fatal cases of Persian fallow deer that were found with heavy tick infestation, we first hypothesized that this infestation predisposed to attack with C. bezziana and myiasis after dermal damage due to ticks; however, in some later cases the deer were infested with $R$. microplus but the myiasis was seen distant from the tick bites, suggesting that this hypothesis might not be true. The primary sites of tick infestation are on the head and neck, so deer were inspected from the top of the head, just rostral to the ear, posteriorly to the scapula, and from the ventral midline to the dorsal midline of the neck (Figure 2). The climatic conditions in the Khuzestan province of Iran are very conducive to a wide variety of parasites, particularly ticks. To the authors' knowledge, this is the first report of $R$. microplus infestation in Persian fallow. The severe infestation of Persian fallow deer reported here further documents the economic impact of $R$. microplus on livestock operations and highlights implications for management.

Cutaneous myiasis, caused by C. bezziana larvae feeding on the cutaneous tissue of their hosts, can result in severe widespread trauma among domestic animals and humans in Southeast Asian and African countries [4]. In this case, although there is a low prevalence of myiasis disease in the villages around the park, the larvae feed on the intact or injured cutaneous tissues of their hosts and cause severe injuries.

The capture and handling of all present deer are frequently required because most are infested with larvae and must be trimmed. After being captured with nets, some deer suffer injuries such as broken locomotors limbs or, in extreme cases, myopathy with recumbency and petechiae in the heart muscle because the capture causes extreme stress and increase their heart rate dangerously. Thus, we strongly recommend the use of Advantek in dart rifles for capture. All of the abovementioned procedures were taught to the staff of the local Nature Preservation of Wild Animals office. 
Citation: Mombeni EG, Mombeini MG, Lahijanzadeh A, Kenarkohi M, Mola SA, et al. (2014) Management and control of an outbreak of fatal truamatic myiasis due to Chrysomya bezziana in a herd of Persian Fallow Deer (Dama dama mesopotamica). J Veterinar Sci Technol 5: 157. doi:10.4172/2157-7579.1000157

Page 4 of 4

In some case internal ophthalmomyiasis have been seen. In this case the larvae penetrate into eye globe and maggots invade the orbit producing severe orbital and eyelids damage (Figure 5).

The Chrysomya bezziana fly lays its eggs in the hair of Persian fallow deer and these then hatch into larvae then penetrate the skin like screws. After the larvae mature, flies burst out of the skin to begin the cycle again. In the current year there have been some ecological and climate validations making the temperature and humidity suitable for increasing the population of $C$. bezziana flies.

C. bezziana incorporate the majority of cases of cutaneous myiasis recorded from Arabia, Africa, India and south-east Asia [7]. Knowledge of the distribution, biology, ecology and behaviour of the forensically important $C$. bezziana fly almost found it at a crime scene defines the post mortem interval in veterolegal cases, especially involving wildlife, but in this protective wildlife area, attacks on live animals by these flies have been seen. Being of forensic importance, this paper is apparently the first report of infestation of cutaneous myiasis due to C. bezziana and fully recommends anaesthesia and treatment of myiasis in Persian fallow deer from south-east Iran, calling for further studies on its prevalence among other wildlife of the country.

\section{Acknowledgement}

The author offers grateful thanks to Dr. Hooshang Ziaie (Iran Department of Environment, Faculty of Natural Environment and Biodiversity) and special thanks to the staff of the Iranian Nature Preservation Organization at Helveh Park in Shush county for their help and hard work in saving these wonderful deer from extinction.

\section{References}

1. Helias SE (2012) Persian Fallow Deer: Rupt.

2. Jantschke $F(1990)$ History of the Persian fallow deer Dama dama mesopotamica at Opel Zoo Kronberg. International Zoo Yearbook, 29: 202-205.

3. Berger-Tal O, Bar-David S, Saltz D (2012) Effectiveness of multiple release sites in reintroduction of Persian fallow deer. Conserv Biol 26: 107-115.

4. Soulsby E (1982)Helminths, arthropods and protozoa of domesticated animals, 7 edn. London: Bailliere and Tindal.

5. Jongejan F, Uilenberg G (2004) The global importance of ticks. Parasitology, 129: S3-S14.

6. Zumpt F (1965) Myiasis in Man and Animals in the Old World. A Textbook for Physicians, Veterinarians and Zoologists. Myiasis in Man and Animals in the Old World A Textbook for Physicians, Veterinarians and Zoologists.

7. Spradbery JP (1991) A manual for the diagnosis of screw-worm fly: Commonwealth Department of Primary Industries and Energy. 